\title{
Does breathing other people's tobacco smoke cause lung cancer?
}

\author{
NICHOLAS J WALD, KIR'AN NANCHAHAL, SIMON G THOMPSON, HOWARD S CUCKLE
}

\begin{abstract}
The available epidemiological studies of lung cancer and exposure to other people's tobacco smoke, in which exposure was assessed by whether or not a person classified as a nonsmoker lived with a smoker, were identified and the results combined. There were 10 case-control studies and three prospective studies. Overall, there was a highly significant $35 \%$ increase in the risk of lung cancer among non-smokers living with smokers compared with non-smokers living with non-smokers (relative risk $1 \cdot 35,95 \%$ confidence interval $1 \cdot 19$ to $1 \cdot 54$ ). Part of this increase was almost certainly caused by the misclassification of some smokers as non-smokers. As smokers, who are more likely to get lung cancer than non-smokers, tend to live with smokers this misclassification probably exaggerated the estimated increase in risk. Adjustment for this error reduced the estimate to $30 \%$ (relative risk $1 \cdot 30$ ), but as people who live with non-smokers may still be exposed to other people's smoke this estimate was revised again to allow for the fact that a truly unexposed reference group was not used. The increase in risk among non-smokers living with smokers compared with a completely unexposed group was thus estimated as $53 \%$ (relative risk of 1.53 ).
\end{abstract}

This analysis, and the fact that non-smokers breathe environmental tobacco smoke, which contains carcinogens, into their lungs and that the generally accepted view is that there is no safe threshold for the effect of carcinogens, leads to the conclusion that breathing other people's tobacco smoke is a cause of lung

\footnotetext{
Department of Environmental and Preventive Medicine, St Bartholomew's Hospital Medical College, London EC1M 6BQ

NICHOLAS J WALD, FFCM, FRCP, professor

KIRAN NANCHAHAL, MSC, research assistant

SIMON G THOMPSON, MA, DIPSTAT, lecturer in medical statistics

HOWARD S CUCKLE, MSC, DPHIL, Cancer Research Campaign senior lecturer

Correspondence to: Professor Wald.
}

cancer. About a third of the cases of lung cancer in non-smokers who live with smokers, and about a quarter of the cases in non-smokers in general, may be attributed to such exposure.

\section{Introduction}

It has been shown that non-smokers who live with smokers are generally more exposed to other people's tobacco smoke, and that their exposure is greater both inside and outside the home, than non-smokers living with non-smokers. ${ }^{1}$ The epidemiological studies that have compared the risk of lung cancer in these two groups of non-smokers therefore provide a valid means of assessing the effect of exposure to environmental tobacco smoke ("passive smoking").$^{2-14}$ Few of the studies have shown a significant risk of lung cancer associated with exposure to such smoke, but this cannot be taken as negative evidence because most of the studies were too small to detect the small excess risk that would be expected. To overcome this problem we present here an analysis that combines the results from all 13 studies. We have also interpreted the collective evidence and judged whether there is a causal association between exposure to environmental tobacco smoke and lung cancer.

\section{Methods}

We reviewed the available epidemiological studies of lung cancer and exposure to environmental tobacco smoke, in which exposure was assessed by whether the subject lived with a smoker (generally taken as having a spouse who was a smoker). In the case-control studies the frequency of living with a smoker was compared in reported lifelong non-smokers with and without lung cancer. In the prospective studies the incidence of lung cancer was compared in reported lifelong non-smokers who lived with a smoker and in those who did not. Three studies were excluded, two because insufficient data on non-smokers were available ${ }^{1516}$ and the other because it used population estimates of smoking prevalence for comparison rather than an explicit control group. ${ }^{17}$ Of the two reports by Koo et al on the same group of subjects, the most recent one has been used for this analysis. ${ }^{1018}$ We thus analysed the 10 remaining case-control studies ${ }^{2-11}$ and three prospective 
studies $^{12-14}$ (see table I). In these studies most of the cases of lung cancer were in women $(990 / 1125)$.

Of the 10 case-control studies, six used hospital controls with diseases that were not related to smoking ${ }^{24679}$ and four used population based controls. $^{581011}$ The controls in all the studies except one were age matched to individual subjects; in the exception the mean ages of cases and controls were similar. ${ }^{4}$ Controls were matched by sex and usually by hospital or geographical area.

Subjects had been ascertained to be non-smokers by interviews of either the subject or the subject's next of kin (usually with a structured questionnaire) except in two studies, which used postal questionnaires alone. ${ }^{112}$ Categorisation of the smoking habits of the person living with the subject differed somewhat between studies. Usually all ex-smokers and current smokers were amalgamated into one smoking category. In studies-for example, that of Trichopolous $\mathrm{et}^{\mathrm{al}} \mathrm{l}^{4}$-where an ex-smoking category was separately defined these data were excluded from our analysis. Most studies excluded unmarried subjects or those living alone, but in a few studies these groups were amalgamated with the category of subjects living with a non-smoker.

Some of the case-control studies obtained relative risk estimates after adjustment for certain factors such as occupation and type of housing. These estimates were virtually identical to those that were unadjusted, indicating that the factors considered were not important. In some studies matched analyses were performed, but again this had no material effect. The published estimates were always close to those calculated in this paper for inclusion in our pooled analysis. In the prospective studies adjustment for age was important, and we therefore used the age adjusted relative risk estimates published by the authors.

The risks of lung cancer of exposed and unexposed subjects are compared here only within each study, and the differences in risk within each study are then combined over all the studies. This avoids directly comparing data from one study with those of another. Details of the statistical analysis are given in the Appendix. In summary, relative risk estimates from each study were combined across studies using published methods. ${ }^{190}$ The method gives a weighting to each of the studies according to the precision of its estimate of risk. For the individual and pooled relative risk estimates $95 \%$ confidence limits were derived from calculations on a $\log$ scale as $\ln$ (relative risk) $\pm(2 \mathrm{SE}$ $(\ln ($ relative risk $))$.

\section{Results}

Table I shows the relative risk estimates of lung cancer associated with exposure to environmental tobacco smoke in the 13 epidemiological studies and the summary estimate based on all the studies combined. Figure 1 shows relative risks and $95 \%$ confidence intervals.

The summary estimate of the increased risk of lung cancer in non-smokers who lived with smokers compared with that in non-smokers who lived with non-smokers was $35 \%$ (relative risk $1 \cdot 35$ ). The $95 \%$ confidence limits of this estimate $(1.19$ to 1.54$)$ indicate that the result is unlikely to have arisen by chance $(p<0.0001)$. The estimate of increased risk from the prospective studies was similar to the estimate from the case-control studies (table I). No relative risk from any one study was inconsistent with the summary relative risk estimate. A formal test for heterogeneity ${ }^{21}$ was not significant $\left(\chi_{19}^{2}=20 \cdot 0\right.$, $\mathrm{p}>0 \cdot 2$ ).

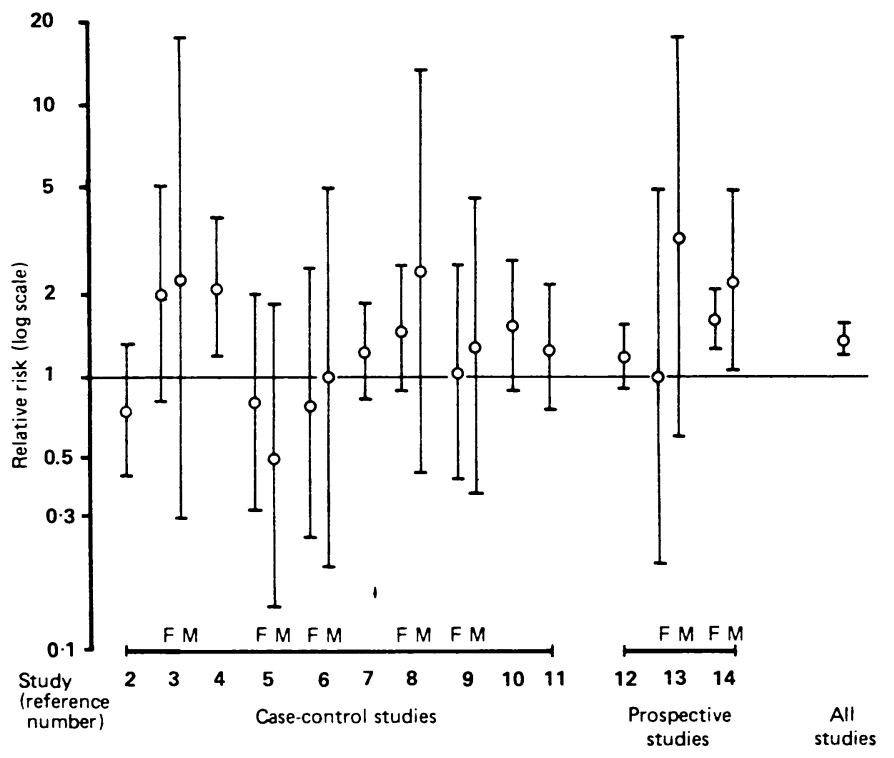

FIG 1-The relative risk of lung cancer (estimate and $95 \%$ confidence interval) in non-smokers who live with smokers compared with non-smokers who live with non-smokers for each of the studies given in table I and the summary estimate based on all the studies combined. The estimate for females is shown first for studies based on both male and female subjects.

TABLE I-Summary of the epidemiological studies of risk of lung cancer in non-smokers associated with exposure to environmental tobacco smoke

\begin{tabular}{|c|c|c|c|c|c|c|c|c|c|}
\hline \multirow[b]{2}{*}{ Authors } & \multirow{2}{*}{$\begin{array}{c}\text { Study } \\
\text { location }\end{array}$} & \multirow[b]{2}{*}{ Sex } & \multicolumn{2}{|c|}{ Exposed to environmental smoke } & \multicolumn{2}{|c|}{ Unexposed to environmental smoke } & \multirow{2}{*}{$\begin{array}{c}\text { Relative } \\
\text { risk }\end{array}$} & \multirow{2}{*}{\multicolumn{2}{|c|}{$\begin{array}{c}95 \% \\
\text { Confidence } \\
\text { limits }\end{array}$}} \\
\hline & & & Lung cancer & No lung cancer & Lung cancer & No lung cancer & & & \\
\hline \multicolumn{10}{|c|}{ Case-control studies } \\
\hline Chan and Fung ${ }^{2}$ & Hong Kong & $\mathrm{F}$ & 34 & 66 & 50 & 73 & 0.75 & 0.43 & $1 \cdot 31$ \\
\hline Correa et $a l^{3}$ & US & $\mathrm{F}$ & 14 & 61 & 8 & 72 & 2.03 & 0.81 & 5.08 \\
\hline & & $\mathbf{M}$ & 2 & 26 & 6 & 154 & $2 \cdot 29$ & 0.30 & $17 \cdot 33$ \\
\hline Trichopoulos et al & Greece & $\mathrm{F}$ & 38 & 81 & 24 & 109 & $2 \cdot 11$ & $1 \cdot 17$ & 3.78 \\
\hline Buffler et al $l^{5}$ & US & $\mathrm{F}$ & 33 & 164 & 8 & 32 & 0.80 & 0.32 & 1.99 \\
\hline & & $\mathbf{M}$ & 5 & 56 & 6 & 34 & 0.50 & 0.14 & 1.83 \\
\hline Kabat and Wynder ${ }^{6}$ & US & $\mathrm{F}$ & 13 & 15 & 11 & 10 & 0.79 & 0.25 & $2 \cdot 48$ \\
\hline & & $\mathbf{M}$ & 5 & 5 & 7 & 7 & 1.00 & $0 \cdot 20$ & 5.06 \\
\hline Garfinkel et al $l$ & US & $\mathrm{F}$ & 91 & 254 & 43 & 148 & $1 \cdot 23$ & 0.81 & $1 \cdot 86$ \\
\hline Akiba et $a l^{3}$ & Japan & $\mathbf{F}$ & 73 & 188 & 21 & 82 & 1.48 & 0.87 & $2 \cdot 52$ \\
\hline & & $\mathbf{M}$ & 3 & 9 & 16 & 101 & $2 \cdot 45$ & 0.45 & $13 \cdot 45$ \\
\hline Lee et al 9 & England & $\mathrm{F}$ & 22 & 45 & 10 & 21 & 1.03 & 0.41 & 2.58 \\
\hline & & $M$ & 8 & 14 & 7 & 16 & $1 \cdot 30$ & 0.37 & 4.54 \\
\hline Koo et $a l^{10}$ & Hong Kong & $\mathrm{F}$ & 51 & 66 & 35 & 70 & 1.54 & 0.89 & $2 \cdot 67$ \\
\hline Pershagen $e t a^{11} \dagger$ & Sweden & $\mathrm{F}$ & 33 & 150 & 34 & 197 & $1 \cdot 27$ & 0.75 & $2 \cdot 18$ \\
\hline \multicolumn{2}{|c|}{ Values overall for case-control studies } & & 425 & & 286 & & $1 \cdot 27$ & 1.05 & 1.53 \\
\hline \multicolumn{10}{|c|}{ Prospective studies } \\
\hline Garfinkel ${ }^{12} \ddagger$ & US & $\mathbf{F}$ & 88 & 127164 & 65 & 49422 & $1 \cdot 18$ & 0.90 & 1.54 \\
\hline Gillis et a $l^{13}$ & Scotland & $\mathrm{F}$ & 6 & 1388 & 2 & 521 & 1.00 & 0.20 & 4.91 \\
\hline & & $\mathbf{M}$ & 4 & 306 & 2 & 515 & $3 \cdot 25$ & 0.60 & $17 \cdot 65$ \\
\hline Hirayama et $a l^{14}$ & Japan & $\mathrm{F}$ & 146 & 63287 & 37 & 21858 & 1.63 & $1 \cdot 25$ & $2 \cdot 11$ \\
\hline & & $M$ & 7 & 1003 & 57 & 19222 & $2 \cdot 25$ & 1.04 & $4 \cdot 86$ \\
\hline \multicolumn{2}{|c|}{ Values overall for prospective studies } & & 251 & & 163 & & $1 \cdot 44$ & $1 \cdot 20$ & $1 \cdot 72$ \\
\hline Values overall for & & & 676 & & 449 & & 1.35 & $1 \cdot 19$ & $1 \cdot 54$ \\
\hline
\end{tabular}

ॠThe method used to calculate the relative risk for the case-control studies and the prospective studies is given in the Appendix.

†Data shown obtained as a personal communication.

$\ddagger$ The number of women not exposed to environmental tobacco smoke was quoted as $28 \%$ of $176739 .{ }^{12}$ 


\section{Discussion}

Our analysis of the epidemiological studies taken together showed an increased risk of lung cancer in non-smokers living with smokers compared with non-smokers living with non-smokers, a result that is unlikely to have arisen by chance. This result must represent either a direct and causal effect of exposure to environmental tobacco smoke or be partly or completely due to bias.

A potentially serious source of bias arises from the probability that some current smokers and ex-smokers will report themselves or be reported by others as never having smoked. They are more likely to develop lung cancer than those correctly classified as lifelong non-smokers and they are also more likely to live with a smoker as couples tend to share the same smoking habits. People reported to be lifelong non-smokers who live with smokers will therefore seem to have an increased risk of lung cancer. In order to quantify the extent to which this misclassification bias could have accounted for the risk found in the epidemiological studies it is necessary to estimate four parameters: the proportion of current and ex-smokers misclassified in this way, the risk of lung cancer in those who are misclassified, the extent to which smokers live with smokers-that is, aggregate together, and the proportion of men and women who have smoked at some time.

\section{PROPORTION OF EVER SMOKERS WHO ARE REPORTED AS} NON-SMOKERS

The proportion of people who say that they have never smoked but are, in fact, likely to be current smokers may be estimated by using the data from studies in which the distributions of nicotine and its metabolite, cotinine, were measured in those who described themselves as non-smokers. Both nicotine and cotinine are derived virtually exclusively from tobacco. Table II summarises the results of four such studies, in which data on smokers were also given. ${ }^{22-24}$ all of these people (93\%) had reported smoking 10 or more years earlier but not more recently, and, on average, they had smoked only about a third as many cigarettes per day as those who reported that they were current smokers and had also reported smoking previously.

From these two sources the proportion of ever smokers who are misclassified as lifelong non-smokers seems to be about $7 \%$ $(2 \cdot 1 \%+4 \cdot 9 \%)$.

\section{RELATIVE RISK OF LUNG CANCER IN CURRENT AND EX-SMOKERS MISCLASSIFIED AS NON-SMOKERS}

In the epidemiological studies considered in this paper nearly $90 \%$ of the cases of lung cancer occurred in women. The study by Hammond showed that women aged 35-74 years who smoked 20 or more cigarettes a day had a 4.9 fold increased risk of lung cancer compared with non-smokers ${ }^{26}$; the study by Doll et al yielded an estimate of 6.4 for women smoking 15-24 cigarettes daily. ${ }^{27}$ Both studies were conducted a number of years ago, and with the increased duration of smoking in women in recent years current estimates of the relative risk would be closer to about 8 . The risk will, however, be much less in both current and ex-smokers who report incorrectly that they are lifelong non-smokers. Such current smokers smoked, on average, only about a quarter as much as other current smokers and might be expected to have an excess risk of lung cancer a quarter as much-that is, an approximate threefold risk of lung cancer $[1+1 / 4(8-1)]$. Ex-smokers who had, in general, given up at least 10 years ago, and therefore had about a quarter of the excess relative risk of continuing smokers ${ }^{28}$ and smoked only a third as much as continuing smokers, will have an even lower risk, say about $1 \cdot 5[1+1 / 4 \times 1 / 3(8-1)]$. The average of 3 and $1 \cdot 5$ weighted according to the relative proportion of current and ex-smokers in those misclassified yields a two fold risk.

TABLE II-Cotinine and nicotine concentrations in non-smokers as markers of misclassification

\begin{tabular}{|c|c|c|c|c|}
\hline Study & Marker & $\begin{array}{c}\text { No of } \\
\text { reported } \\
\text { non-smokers }\end{array}$ & $\begin{array}{l}\text { No of } \\
\text { reported } \\
\text { smokers }\end{array}$ & $\begin{array}{l}\text { No }(\%) \text { of non-smokers with } \\
\text { marker concentration }>10 \% \text { of } \\
\text { smokers' concentration }\end{array}$ \\
\hline $\begin{array}{l}\text { Feyerabend et } a l^{22} \\
\text { Wald } \text { et }^{2} \mathbf{l}^{23} \\
\text { Pojer } \text { et al }{ }^{24} \\
\text { Haddow } \text { et } a l\end{array}$ & $\begin{array}{l}\text { Urinary nicotine } \\
\text { Urinary cotinine } \\
\text { Plasma cotinine } \\
\text { Serum cotinine }\end{array}$ & $\begin{array}{r}56 \\
221 \\
181 \\
232\end{array}$ & $\begin{array}{r}82 \\
131 \\
187 \\
305\end{array}$ & $\begin{array}{l}0 \\
2(0 \cdot 9) \dagger \\
6(3 \cdot 3) \neq \\
3(1 \cdot 3) \emptyset\end{array}$ \\
\hline Total & & 690 & 705 & $11(1 \cdot 6)$ \\
\hline
\end{tabular}

*Smokers' median concentration (mean concentration in the study of Feyerabend $e t a l$ ).

$+19 \%$ and $24 \%$ of smokers' concentration.

Three $10-14 \%$, one $15-29 \%$, two $30-44 \%$ of smokers' concentration (individual values not specified).

$14 \%, 16 \%$, and $68 \%$ of smokers' concentration.

|Personal communication.

In all, there were 690 people who described themselves as non-smokers, 11 of whom $(1 \cdot 6 \%)$ had concentrations of nicotine or cotinine greater than a tenth of the median concentration (or, in one study, the mean) found in smokers, though these 11 had still on average only about a quarter of that median concentration in smokers. If, as is the case for women in Britain, about $50 \%$ are reported never to have smoked, ${ }^{25} 35 \%$ to be current smokers, and $15 \%$ to be ex-smokers then $2 \cdot 1 \%$ of ever smokers $(1 \cdot 6 \% \times(50 \%+15 \%) /(35 \%+15 \%))$ may be current smokers who are not classified as such.

The proportion of ever-smokers who, though ex-smokers, are reported never to have been smokers was estimated in the Medical Research Council national survey of health and development (N Britten, personal communication). In this study information on smoking was collected on several occasions from 3274 of the subjects from the survey. Of all the subjects who had previously reported that they smoked, $4.9 \%$ said in their most recent interview that they had never smoked as much as one cigarette a day. Nearly

\section{AGGREGATION OF SMOKERS}

The extent to which smokers live with other smokers can be expressed numerically as the odds ratio in a $2 \times 2$ table categorising the smoking state of the subject by the smoking state of those with whom the subject lives. We call this ratio the aggregation factor. It was estimated to be 3.94 based on interviews with 364 subjects (table III), $2 \cdot 22$ based on a study of 4064 subjects, ${ }^{13} 3 \cdot 55$ for men and 3.07 for women based on a study of 8800 subjects (P N Lee, unpublished findings). We have adopted a figure of $3 \cdot 0$.

\section{PROPORTION OF MEN AND WOMEN WHO HAVE SMOKED AT SOME} TIME

The proportions of men and women in the population who have smoked at some time influences the extent of the misclassification bias; the greater the proportions (of women in particular), the greater the bias. We chose quite high proportions in the calculations 
TABLE III-Number of smokers and non-smokers ${ }^{\star}$ related to smoking habits of their spouses and the odds ratio indicating the extent of aggregationt

\begin{tabular}{lccc}
\hline & \multicolumn{3}{c}{ Subject } \\
\cline { 2 - 3 } \multicolumn{1}{c}{ Spouse } & Ever smoker & Lifelong non-smoker & Total \\
\hline Ever smoker & 84 & 13 & 97 \\
Lifelong non-smoker & 164 & 100 & 264 \\
\hline \multicolumn{1}{c}{ Total } & 248 & 113 & 361 \\
\hline
\end{tabular}

*Based on interviews of 200 women and 164 men attending a health screening centre in London or working in the civil service in Newcastle in 1985, excluding three people who lived alone.

†Aggregation factor $=3.94$

-namely, $50 \%$ of women and $70 \%$ of men-representative of the higher figures in the countries in which the studies on exposure to environmental tobacco smoke were carried out as this tends to overestimate rather than underestimate the effect of the bias.

Figure 2 shows how, on the basis of these four estimates, the relative risk of lung cancer in association with exposure to environmental tobacco smoke of 1.35 (the overall estimate from table I) would be observed if the true relative risk for non-smokers exposed to such smoke was $1 \cdot 30$. Under these conditions the $95 \%$ confidence limits of 1.19 to 1.54 for the observed relative risk of 1.35 correspond to limits of $1 \cdot 14$ to 1.50 for the estimated true relative risk of $1 \cdot 30$. The misclassification bias is therefore unlikely to account for all the association between lung cancer and exposure to this type of smoke.

Table IV illustrates the effect of adopting different estimates of the variables that affect the misclassification bias by showing the proportion of ever smokers who would need to be misclassified as lifelong non-smokers to account for observed relative risks from $1 \cdot 4$ to $1 \cdot 1$. In particular, table IV may be used to determine how large $\underline{\underline{T}}$ these estimates would have to be to account completely for the 3 observed increase in risk. Lee has produced a similar illustration of $\mathbb{\mathbb { Q }}$ the bias ${ }^{29}$ but believes (unpublished findings) that its effect is greater $c$ than we do, mainly because he assumed a higher rate of mis- $\bar{\partial}$ classification (more than $12 \%$ of those who reported themselves to $\bar{\exists}$ be non-smokers) and applied to misclassified smokers what we $D$ consider to be too high a risk of lung cancer-in particular, a 10 fold 8 relative risk in the $1.4 \%$ of misclassified current smokers.

The possibility of a dose response relation between exposure to

TABLE IV-Proportion (\%) of ever smokers misclassified as lifelong non-smokers that would be needed to convert specified observed relative risks of lung cancer associated with exposure to environmental tobacco smoke to unity according to the extent of smoker aggregation and the relative risk of lung cancer in ever smokers misclassified as non-smokers

\begin{tabular}{|c|c|c|c|c|}
\hline \multirow{2}{*}{$\begin{array}{l}\text { Observed relative risk of } \\
\text { lung cancer in studies of exposure } \\
\text { to environmental tobacco smoke }\end{array}$} & \multirow{2}{*}{$\begin{array}{l}\text { Aggregation } \\
\text { factor }\end{array}$} & \multicolumn{3}{|c|}{$\begin{array}{l}\text { Relative risk of lung cancer in those } \\
\text { misclassified as lifelong non-smoker }\end{array}$} \\
\hline & & 2 & 4 & 8 \\
\hline $1 \cdot 4$ & $\left\{\begin{array}{l}2 \\
3 \\
4\end{array}\right.$ & $\stackrel{\star}{\star}$ & $\begin{array}{c}\star \\
36 \cdot 0 \\
20 \cdot 0\end{array}$ & $\begin{array}{l}\star \\
9 \cdot 5 \\
6 \cdot 8\end{array}$ \\
\hline $1 \cdot 3$ & $\left\{\begin{array}{l}2 \\
3 \\
4\end{array}\right.$ & $\stackrel{\star}{\star}$ & $\begin{array}{l}\star \\
18 \cdot 0 \\
13 \cdot 0\end{array}$ & $\begin{array}{r}14 \cdot 0 \\
6 \cdot 3 \\
4 \cdot 7\end{array}$ \\
\hline $1 \cdot 2$ & $\left\{\begin{array}{l}2 \\
3 \\
4\end{array}\right.$ & $\begin{array}{c}\star \\
73 \\
34\end{array}$ & $\begin{array}{r}20 \cdot 0 \\
9 \cdot 7 \\
7 \cdot 4\end{array}$ & $\begin{array}{l}6 \cdot 7 \\
3 \cdot 8 \\
3 \cdot 0\end{array}$ \\
\hline $1 \cdot 1$ & $\left\{\begin{array}{l}2 \\
3 \\
4\end{array}\right.$ & $\begin{array}{l}31 \\
15 \\
11\end{array}$ & $\begin{array}{l}6 \cdot 9 \\
4 \cdot 2 \\
3 \cdot 3\end{array}$ & $\begin{array}{l}2 \cdot 8 \\
1 \cdot 7 \\
1 \cdot 4\end{array}$ \\
\hline
\end{tabular}

${ }^{\star}$ Even $100 \%$ misclassification would not give the observed relative risk.

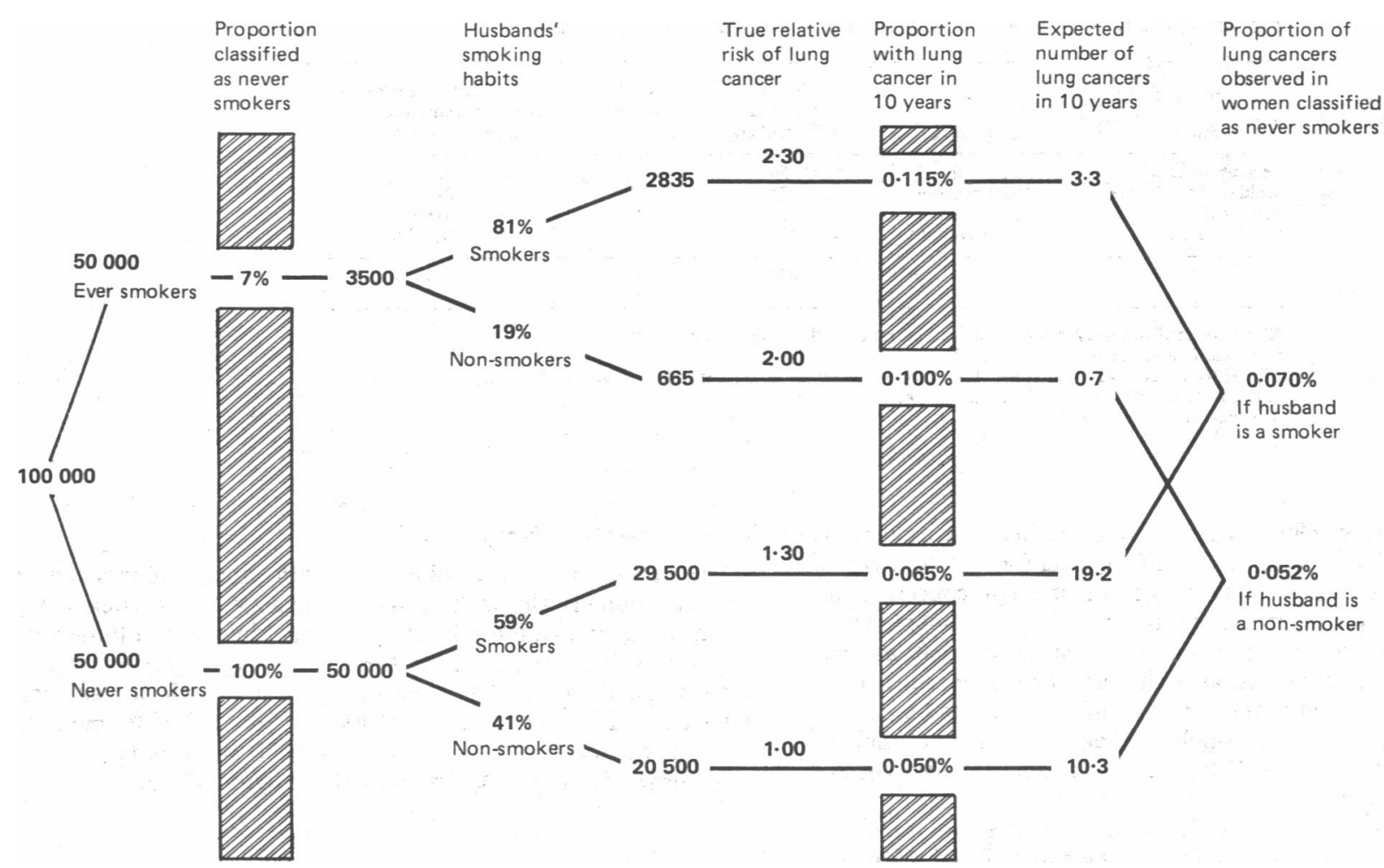

FIG 2-Illustration of how the misclassification bias transforms a true relative risk of lung cancer of $1 \cdot 30$ to an observed relative risk of $1 \cdot 35$ in non-smoking women, comparing those married to smokers with those married to non-smokers assuming that: $(a)$ the proportion of current and ex-smokers misclassified as non-smokers is $7 \%$; (b) the true relative risk of lung cancer among women misclassified as non-smokers is $2 \cdot 0$ for those married to non-smokers and $2 \cdot 30$ for those married to smokers; $(c)$ the aggregation factor of smoking state within marriages is 3.0 (see text and table III); and (d) the proportion of ever smokers is $50 \%$ for women and $70 \%$ for men, which, with an aggregation factor of 3, determines the estimates of a husband's smoking habits according to the woman's smoking; $3=(81 \% \times 41 \%) /(19 \% \times 59 \%)$. (The lung cancer incidence of $0.050 \%$ per 10 years in non-smoking women was chosen for illustration but does not affect the conclusion.) 
environmental tobacco smoke (assessed by the amount and duration of a partner's smoking) and lung cancer was investigated in eight of the epidemiological studies ${ }^{34810-13}$ and identified in five. ${ }^{347811}$ This supports a causal explanation, but the evidence is weak. It could also be explained by bias if smokers, some of whom had been misclassified as non-smokers, had a cigarette consumption (and therefore a lung cancer risk) that was correlated with the cigarette consumption of the person with whom they lived.

Other potential sources of bias are unlikely to have distorted the estimate of risk. In the case-control studies cases may have denied smoking more than controls or their interviewers may have investigated their non-smoking status to a different extent. There is no evidence to suggest this, and indeed the prospective studies which by design avoided this bias yielded similar results to the casecontrol studies. Positive studies may have been more likely to have been published than negative ones. We are, however, unaware of unpublished negative studies, and once the initial positive studies had been reported the incentive to publish negative studies was at least as great as that to publish positive ones. We conclude, therefore, that at least part of the association is causal, and our best estimate is that the excess risk of lung cancer due to exposure to environmental tobacco smoke, as judged by the difference in exposure in those who do and those who do not live with smokers, is about $30 \%$ (relative risk $1 \cdot 30$ ).

This figure is an underestimate of the true risk of exposure to environmental tobacco smoke typical of those who live with smokers because some of the non-smokers who live with nonsmokers and who are not exposed to such ambient smoke at home are exposed to it in other settings-for example, at work. The relative risk estimate of 1.30 is therefore based on a reference group that is partially exposed. This can be allowed for to some extent by the use of data on urinary cotinine concentrations in non-smokers living with smoking or non-smoking partners. In the study by Wald and Ritchie the average urinary cotinine concentration among non-smokers married to smokers was about three times that among non-smokers married to non-smokers. 'If $y$ is the excess lung cancer risk in non-smokers living with non-smokers then, assuming a linear relation between the excess risk in non-smokers and the extent of exposure, the excess lung cancer risk in non-smokers living with smokers is $3 \mathrm{y}$ and the relative risk of 1.30 above must satisfy the equation $1 \cdot 30=(1+3 y) /(1+y)$. When the equation is solved $y=0 \cdot 176$, and the excess risk in non-smokers living with smokers may be estimated as $53 \%(3 y \times 100 \%)$ and in non-smokers living with non-smokers as $18 \%(y \times 100 \%)$. This estimate of increased risk would indicate that about a third of cases of lung cancer in non-smokers living with smokers, and about a quarter of cases in non-smokers in general, may be attributed to exposure to environmental tobacco smoke. (The excess risk divided by the total risk for non-smokers living with non-smokers is $0.53 / 1.53$, or about a third, and for non-smokers in general is $0.38 / 1 \cdot 38$, or about a quarter; 0.38 is an average of the excess risks of 0.53 and 0.18 weighted according to the estimated proportions of spouses who had smoked at some time.)

The effect of exposure to such smoke on lung cancer may be estimated from data on biological markers in smokers. We have avoided performing a detailed analysis of this kind as it entails several assumptions that with present knowledge are difficult to support-for example, as to the quantitative relation between nicotine in ambient smoke and in mainstream smoke and the relation of these values to the concentration of the carcinogens in tobacco smoke. It is, however, pertinent that in non-smokers who live with a smoker urinary cotinine concentrations are about $1 \%$ of those found in active smokers. ${ }^{23}{ }^{30}$ In the study that examined urinary cotinine concentrations in cigarette smokers and in non-smokers classified according to whether or not they lived with smokers, further analysis showed that the mean concentrations were in the ratio $200: 3: 1$, respectively. This ratio is broadly in line with the excess risk of lung cancer in the three groups-namely, 13, 0.3 , and 0 , respectively, suggesting that the observed risk is reasonably consistent with what might be expected. (We used the figure of 13 here, instead of 7 , as it relates to men, ${ }^{31}$ and $(a)$ in the cotinine study all the smokers were men and $(b)$ in women living with a smoker the number of years of exposure is likely to be closer to the number of years of smoking among men than among women.)

We conclude that breathing other people's tobacco smoke does cause lung cancer, and our conclusion rests on several observations. Firstly, carcinogens in tobacco smoke are released into the air. Secondly, tobacco smoke is breathed into the lungs by nonsmokers. Thirdly, the general view is that exposure to carcinogens does not have a threshold below which there is no effect. Fourthly, people known to have an increased exposure to environmental tobacco smoke seem to have an excess risk of lung cancer, which is not explained satisfactorily by bias. Fifthly, the magnitude of the excess seems reasonable in view of the extent of exposure, and, sixthly, there is a dose response relation between the extent of exposure and risk. In view of all these observations, we could not have concluded otherwise.

This paper was produced while one of the authors (NJW) was a member of the National Academy of Science Committee on Passive Smoking (Chairman Barbara Hulka), which has produced a report, Environmental Tobacco Smoke: Measuring Exposure and Assessing Health Effects, to be published shortly by the National Academy. We would like to thank members of that committee, particularly James Robins, and Diane Wagener and Marvin Schneidermann on the secretariat of the committee, for their constructive criticism and help in developing the ideas expressed in this paper. We also thank Jane Stock for collection of data, Nicky Britten, Linda Koo, and Goran Pershagen for allowing us to use their unpublished data, Malcolm Law for his comments, and the Cancer Research Campaign and the British United Provident Association for their financial support.

\section{References}

1 Wald NJ, Ritchie C. Validation of studies on lung cancer in non-smokers married to smokers. Lancet 1984;i:1067.

2 Chan WC, Fung SC. Lung cancer in non-smokers in Hong Kong. Cancer Campaign. In Grundmann E, ed. Cancer epidemiology. Vol 6. New York: Gustav Fischer Verlag, 1982 199-202.

3 Correa P, Pickle LW, Fontham E, Lin Y, Haenszel W. Passive smoking and lung cancer. Lancet $1983 ;$ ii: $595-7$.

4 Trichopolous D, Kalandidi A, Sparros L. Lung cancer and passive smoking: conclusion of Greek study. Lancet $1983 ;$ ii: $667-8$.

5 Buffler PA, Pickle LW, Mason TJ, Contant C. The causes of lung cancer in Texas. In: Mizell M, Correa P, eds. Lung cancer: causes and prevention. New York: Verlag Chemie International, 1984:83-99.

6 Kabat GC, Wynder EL. Lung cancer in nonsmokers. Cancer 1984;53:1214-21.

6 Kabat GC, Wynder EL. Lung cancer in nonsmokers. Cancer 1984;53:1214-21. foumal of the National Cancer Institute 1985;75:463-9.

8 Akiba S, Kato H, Blot WJ. Passive smoking and lung cancer among Japanese women. Cancer Res 1986;46:4804-7.

9 Lee PN, Chamberlain J, Alderson MR. Relationship of passive smoking to the risk of lung cancer and other smoking-associated diseases. Brf Cancer 1986;54:97-105.

10 Koo LC, Ho JH-C, Fraumeni JF, Blot WJ, Lubin JH, Stone BJ. Measurements of passive smoking and estimates of risk for lung cancer among non-smoking Chinese females. International fournal of Cancer (in press)

11 Pershagen G, Hrubec Z, Svensen C. Passive smoking and lung cancer in Swedish women. Am $\mathcal{f}$ Epidemiol (in press).

12 Garfinkel L. Time trends in lung cancer mortality among nonsmokers and a note on passive smoking. Fournal of the National Cancer Institute 1981;66:1061-6.

13 Gillis CR. Hole DJ, Hawthorne VM, Boyle P. The effect of environmental tobacco smoke in two urban communities in the west of Scotland. Eur F Respir Dis [Suppl] 1984;133:121-6.

14 Hirayama $T$. Cancer mortality in nonsmoking women with smoking husbands in a large-scale cohort study in Japan. Prev Med 1984;13:680-90.
cons

15 Sandler DP, Everson RB, Wilcox AJ. Passive smoking in adulthood and cancer risk. Am $f$ Epidemiol 1985;121:37-48.

$16 \mathrm{Wu}$ AH, Henderson BE, Pike MC, Yu MC. Smoking and other risk factors for lung cancer in women. Journal of the National Cancer Institute 1985;74:747-51.

17 Knoth A, Bohn H, Schmidt F. Passivrauchen als Lungenkrebasursage bei Nichtraucherinnen. Medisinische Klinik 1983;78:54-9.

$18 \mathrm{Koo} \mathrm{LC}, \mathrm{Ho} \mathrm{JH}$, Lee N. An analysis of some risk factors for lung cancer in Hong Kong. Int $\mathcal{f}$ Cancer 1985;35:149-55.

9 Yusuf S, Peto R, Lewis J, Collins R, Sleight P. Beta-blockade during and after myocardia infarction: an overview of the randomized trials. Prog Cardiovasc Dis 1985;27:335-71.

20 Kleinbaum DG, Kupper LL, Morgenstern H. Epidemiological research: principles and quantitative methods. New York: Van Nostrand Rheinhold, 1982:341-2.

21 Woolf B. On estimating the relation between blood group and disease. Ann Hum Genet 1955;19:251-3.

22 Feyerabend C, Higenbottam T, Russell MAH. Nicotine concentrations in urine and saliva of smokers and non-smokers. Br Med $\mathcal{F}$ 1982;284:1002-4.

23 Wald NJ, Boreham J, Bailey A, Ritchie C, Haddow JE, Knight G. Urinary cotinine as a marker of breathing other people's tobacco smoke. Lancet 1984;i:230-1.

24 Pojer R, Whitfield JB, Poulous V, Eckhard IF, Richmond R, Hensley WJ. Carboxyhemoglobin, Pojer R, Whitfield JB, Poulous V, Eckhard IF, Richmond R, Hensley WJ. Carboxyhemoglobin,
cotinine, and thiocyanate assay compared for distinguishing smokers from non-smokers. Clin cotinine, and thiocyanate

25 Office of Population Censuses and Surveys. General household survey 1982. London: HMSO, 1984. 26 Hammond EC. Smoking in relation to the death rate of one million men and women. National Cancer Institute Monographs 1966;19:127-204.

27 Doll R, Gray R, Hafner B, Peto R. Mortality in relation to smoking: 22 years' observations on female British doctors. Br Med f 1980;280:967-71.

28 Doll R. Practical steps towards the prevention of bronchial carcinoma. Scot Med J 1970;15: 433-47. 
29 Lehnert G, Garfinkel L, Hirayama T, et al. Round table discussion from symposium on medical perspectives on passive smoking (Vienna, April 1984). Prev Med 1984;13:732-3.

30 Russell MAH, Jarvis MJ, West RJ. Use of urinary nicotine concentrations to estimate exposure and mortality from passive smoking in non-smokers. British foumal of Addiction 1986;81 $275-81$

31 Doll R, Peto R. Mortality in relation to smoking: 20 years' observation on male British doctors. $B r$ Med F 1976;ii: 1525-30.

(Accepted 30 October 1986

\section{Appendix}

Let the number of subjects in each of the epidemiological studies be classified by disease status and exposure in this way:

\begin{tabular}{lccc}
\hline & With lung cancer & Without lung cancer & Total \\
\hline Living with a smoker & $\mathrm{a}$ & $\mathrm{b}$ & $\mathrm{m}_{1}$ \\
Living with a non-smoker & $\mathrm{c}$ & $\mathrm{d}$ & $\mathrm{m}_{2}$ \\
\hline Total & $\mathrm{m}_{3}$ & $\mathrm{~m}_{4}$ & $\mathrm{~T}$
\end{tabular}

The relative risk of lung cancer in association with living with a smoker (and its confidence limits) were then calculated as follows:

For each of the case-control studies-In the absence of a risk from exposure to environmental tobacco smoke the expected number of people (E) who live with a smoker and have lung cancer is $m_{1} m_{3} / T$. The difference $(\mathrm{O}-\mathrm{E})$ between observed $(\mathrm{O})$ and expected $(\mathrm{E})$ numbers of people with lung cancer who live with a smoker was calculated, the variance of this difference being

$$
\operatorname{Var}(\mathrm{O}-\mathrm{E})=\frac{\mathrm{m}_{1} \times \mathrm{m}_{2} \times \mathrm{m}_{3} \times \mathrm{m}_{4}}{\mathrm{~T} \times \mathrm{T} \times(\mathrm{T}-1)}
$$

The natural logarithm of the relative risk (RR) was estimated for each study using ${ }^{19}$

$$
\ln R R=\frac{O-E}{\operatorname{Var}(O-E)}
$$

Confidence limits for $\ln \mathrm{RR}$ were calculated using the variance

$$
\operatorname{Var}(\ln \mathrm{RR})=1 / \operatorname{Var}(\mathrm{O}-\mathrm{E})
$$

and the estimate of RR and its confidence limits were estimated from the calculations on a logarithmic scale by exponentiation.

For each of the prospective studies-For prospective studies the published relative risk values were used in the following calculations as in all of the articles the authors had estimated the relative risk, adjusting for variables such as age. For those studies in which relative risk estimates were given separately for different levels of smoking by the spouse ${ }^{1214}$ a combined estimate of relative risk was calculated as an average of the individual estimates, each weighted inversely proportional to its variance. (See method below for combining the prospective studies.) The variance of the natural logarithm of the relative risk was derived from the published confidence limits for the estimate of relative risk in all studies except one $^{13}$ (where adjustment for age seemed of little importance and no confidence limits had been published), in which the method given above for the case-control studies was used.

For combining the results from the studies-The method used for combining the results from the case-control studies is based on that of Yusuf $\mathrm{et} \mathrm{al.}{ }^{19}$ The overall estimate of RR was calculated by adding the values of $(\mathrm{O}-\mathrm{E})$ and their variances for all the studies and using

$$
\ln \mathrm{RR}=\frac{\Sigma(\mathrm{O}-\mathrm{E})}{\Sigma \operatorname{Var}(\mathrm{O}-\mathrm{E})}
$$

and for the variance

$$
\operatorname{Var}(\ln \mathrm{RR})=\frac{1}{\Sigma \operatorname{Var}(\mathrm{O}-\mathrm{E})}
$$

The method used for combining the results from the prospective studies is based on a pooled value for the $\ln R R$ calculated as an average of the individual $\ln \mathrm{RRs}$, each inversely weighted according to its variance..$^{20}$

$$
\ln R R=\sum \frac{(\ln R R)}{\operatorname{Var}(\ln R R)} / \sum \frac{1}{\operatorname{Var}(\ln R R)}
$$

and for the variance

$$
\operatorname{Var}(\ln R R)=\frac{1}{\sum \frac{1}{\operatorname{Var}(\ln R R)}}
$$

The overall value for the $\ln R R$ in all of the studies combined was obtained using the same method that was used to pool results from the prospective studies, using the overall values for the case-control and prospective studies.
Can Fybogel sachets (Ispaghula husk) be taken indefinitely?

I know of no documented or anecdotal evidence of long term ill effects from taking ispaghula over many years. The only theoretical problem is of reduced calcium absorption which might lead to an increased risk of osteoporosis. Faecal calcium excretion is increased by any form of extra fibre; a short term study showed such an increase during the ingestion of ispaghula and of bran but the changes did not reach statistical significance. ${ }^{1}$ It is unlikely that this would be an adverse effect of any practical importance.-JOHN R BENNETT, consultant physician, Kingston upon Hull.

1 Smith RG, Rowe MJ, Smith AN, et al. A study of bulking agents in elderly patients. Age and Ageing 1980;9:267-71.

Can non-steroidal anti-inflammatory drugs cause tinnitus?

Tinnitus has been reported as a side effect of treatment with most, if not all, non-steroidal anti-inflammatory drugs. Most of the reports have been on clinical trials rather than as well documented case reports. The Committee On Safety Of Medicines has had a few reports with most non-steroidal antiinflammatory drugs. The incidence appears to be low, and there is no good evidence that one non-steroidal anti-inflammatory drug is more likely to have this effect than another. In some cases tinnitus has been accompanied by sensorineural deafness which is usually reversible though one case of irreversible deafness has been reported with piroxicam. ${ }^{1}$ I was unable to find any studies of the mechanism of this effect, but aspirin produces dose related cochlear toxicity characterised by depolarisation of the cochlear apparatus with reduced hearing over the whole frequency range. ${ }^{2}$ - LINDA BEELEY, consultant clinical pharmacologist, Birmingham.

1 Vernick DM, Kelly JH. Sudden hearing loss associated with piroxicam. Am f Otol 1986;7:97-8. 2 Dukes MNG, ed. Meyler's side effects of drugs. 10th ed. Amsterdam-New York-Oxford: Elsevier, 1984:143.

\section{Correction}

Severe hypermagnesaemia due to magnesium sulphate enemas in patients with hepatic coma

We regret that an error occurred in this paper by Dr P O Collinson and Dr A K Burroughs (18 October, p 1013). In figure 2 it is stated that calcium is represented by blocked circles and magnesium by blocked squares. It should have said that calcium is represented by blocked squares and magnesium by blocked circles. 